\title{
OPEN Publisher Correction: Combining Biomarkers with EMR Data to Identify Patients in Different Phases of Sepsis
}

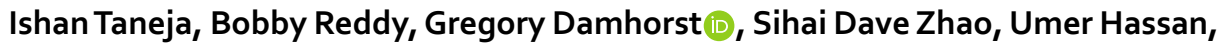

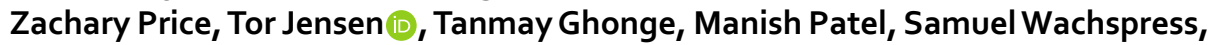
Jackson Winter, Michael Rappleye, Gillian Smith, Ryan Healey, Muhammad Ajmal, Muhammad Khan, Jay Patel, Harsh Rawal, Raiya Sarwar(D, Sumeet Soni, Syed Anwaruddin, Benjamin Davis, James Kumar, Karen White, Rashid Bashir \& Ruoqing Zhu

Correction to: Scientific Reports https://doi.org/10.1038/s41598-017-09766-1, published online 07 September 2017

The Competing Interests statement in the original version of this Article incorrectly stated that "The authors declare that they have no competing interests". The Competing Interests statement now reads:

"Ishan Taneja, Bobby Reddy Jr. and Samuel Waschpress work for Prenosis Inc.. Jackson Winter worked at Prenosis at the time of submission but has since left and is now a graduate student at the University of Illinois at Urbana-Champaign. All other authors report no competing interests."

In addition, the author Jackson Winter was incorrectly given as Jake Winter.

These errors have now been corrected in the HTML and PDF versions of the Article, and in the accompanying supplementary material.

(i) Open Access This article is licensed under a Creative Commons Attribution 4.0 International License, which permits use, sharing, adaptation, distribution and reproduction in any medium or format, as long as you give appropriate credit to the original author(s) and the source, provide a link to the Creative Commons license, and indicate if changes were made. The images or other third party material in this article are included in the article's Creative Commons license, unless indicated otherwise in a credit line to the material. If material is not included in the article's Creative Commons license and your intended use is not permitted by statutory regulation or exceeds the permitted use, you will need to obtain permission directly from the copyright holder. To view a copy of this license, visit http://creativecommons.org/licenses/by/4.0/.

(C) The Author(s) 2019 